\title{
A Rare but Fatal Complication Probably due to Imatinib: Cerebral Edema
} Ozgur Mehtap ${ }^{1}$, Elif Birtas Atesoglu', Pinar Tarkun¹, Abdullah Hacihanefioglu1*, Hakan Keski ${ }^{1}$ and Sehnaz Basaran²

${ }^{1}$ Medical Faculty, Department of Hematology, University of Kocaeli, Turkey

${ }^{2}$ Medical Faculty, Department of Neurology, University of Kocaeli, Turkey

\begin{abstract}
Imatinib mesylate is a tyrosine kinase inhibitor that strongly inhibits the tyrosine kinases like BCR-ABL1, KIT and PDGFRB and is used in the treatment of chronic myeloid leukemia. As well as its proven effectiveness its frequent side effects are also well known. Apart from its other side effects its commonly encountered side effect in daily clinical use is edema. Although the path-physiology of this process has not yet been well understood, its strong blocking action on PDGFRB is thought to be responsible. In this case report we are presenting a chronic myeloid leukemia patient with cerebral edema who unfortunately died. To our knowledge, she has been the third patient who was reported due to this complication of imatinib. As we could not estimate another cause we strongly deduced that the cerebral edema was due to imatinib.
\end{abstract}

Keywords: Imatinib; Tyrosine kinase inhibitor; Cerebral edema

\section{Introduction}

Imatinib mesylate (STI571) is a selective inhibitor of the tyrosine kinases like BCR-ABL1, KIT and PDGFRB (platelet derived growth factor-beta subunit) [1]. Imatinib is the first molecule that is used directly to the target using its tyrosine kinase inhibiting property [2]. By the published results of the International Randomized Study of Interferon vs. STI 571 (IRIS) study in 2002, imatinib has gained acceptance in the treatment of the newly diagnosed chronic myeloid leukemia (CML) patients. By the first line treatment with imatinib the haematologic response obtained reaches to $98 \%$ and the complete cytogenetic response reaches to $65-85 \%$ [3-5]. Moreover imatinib is shown to be effective in the blastic phase of CML for a short time [6]. Imatinib is also used with success in the treatment of the gastrointestinal stromal tumors (GIST) $[7,8]$.

Imatinib is usually well tolerated however mild to moderate adverse effects are not infrequent (less than 10\%). The most commonly encountered adverse effects of imatinib are muscular pain cramps, myelosuppression, nausea, vomiting, cutaneous lesions and periorbital or pretibial edema [3,5,9-11]. Localized fluid retentions or edema from mild to moderate level usually respond well to diuretics and sodium restriction however more rare but more serious adverse effects of imatinib have been described; optic disc edema [12,13], intramuscular edema [14], pleural or pericardial effusions [15] and intra-articular effusion [16] are among these. Another very rare adverse effect which can be fatal as well and that is most possibly related to imatinib is cerebral edema [17]. In this manuscript we are presenting a CML patient with cerebral edema who had been given imatinib.

\section{Case Report}

A 36 year old woman was diagnosed to have CML at the chronic phase and she was put on imatinib therapy $400 \mathrm{mg} / \mathrm{d}$ on the 30th of October, 2008. She applied to the haematology out-patient ward 15 days after the commencement of therapy with the complaint of having headache. Her headache had increased during the last few days with resistance to the analgesics. Furthermore she started to have nausea and vomiting, as well. As her headache was specially localized in the periorbital area and as she started to complain of blurred vision, increasing light sensitivity she was consulted by an ophthalmologist that unveiled bilateral grade 4 papilledema. She underwent a cranial $\mathrm{CT}$ on the same day with the suspicion of leukemic involvement or any other intracranial event (29 November, 2008) however nothing but cerebral edema was found and hence the patient was hospitalized in the neurology department. The control cerebral CT that was performed on the 1st of December, 2008 showed cerebellar tonsillar herniation in addition to the findings of cerebral edema (Figure 1). The patient was not receiving any other drugs at the time and there was no other known pathology (i.e. intoxication, vasculitis, metabolic disease, intracranial haemorrhage) that could have been held responsible for cerebral edema. So we thought that imatinib would be responsible for the edema and hence the drug was discontinued immediately and she was put on an anti-edema therapy (mannitol $150 \mathrm{cc}, 4$ times a day and

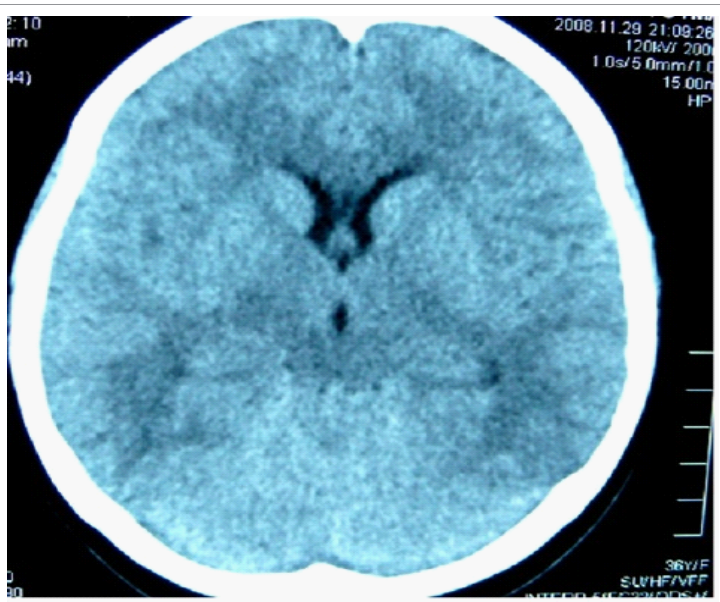

Figure 1: Cranial CT (01.12.2008): Effacement in cerebral sulcii and gyrii. The ventricles appear compressed, loss of the gray-white matter junction and lenticular nucleus differentiation. These findings are concordant with brain edema.

*Corresponding author: Abdullah Hacihanefioglu, Faculty of Medicine Department of Hematology, Kocaeli University, Umuttepe Campus, P.O.- 41380 Kocaeli, Turkey, Tel: +90-262-3038238/7522; Fax: +90-262-3038003; E-mail: bsukriye@hotmail.com

Received June 07, 2012; Accepted July 20, 2012; Published July 23, 2012

Citation: Mehtap O, Atesoglu EB, Tarkun P, Hacihanefioglu A, Keski H, et al (2012) A Rare but Fatal Complication Probably due to Imatinib: Cerebral Edema. J Clin Case Rep 2:176. doi:10.4172/2165-7920.1000176

Copyright: @ 2012 Mehtap O, et al. This is an open-access article distributed under the terms of the Creative Commons Attribution License, which permits unrestricted use, distribution, and reproduction in any medium, provided the original author and source are credited. 
diasomide tablet, $250 \mathrm{mg}$, 4 times a day).The cranial MRI performed on the 3rd of December, 2008 displayed cerebral edema, volume increase in the white matter and T2 signal augmentation (Figure 2). There were no signs of vasculitis, thrombosis or leukemic involvement. Dexametasone $4 \mathrm{mg}$, twice a day was added to the treatment protocol. The patient was consulted with the neurosurgery department in terms of a surgical therapy but she was not considered to be suitable for a surgical intervention. As the patient's headaches subsided 4 days after her hospitalization, she was discharged on the 15th of December, 2008 with the prescription of dexametasone $4 \mathrm{mg}$ twice a day. We planned to start another tyrosine kinase inhibitor instead of imatinib however 9 days after her discharge the patient applied to the emergency service with a severe headache. CT scan taken again on the 23rd of December, 2008 displayed the findings consistent with diffuse cerebral edema. The patient lost her consciousness in a short while and on the 25 th of December, 2008 she died after respiratory arrest which was followed by a cardiac arrest.

\section{Discussion}

Here we are presenting a patient with CML in whom a fatal outcome ensued on the 15th day of her therapy with imatinib. The patient was suffered from increased intracranial pressure symptoms and signs as mentioned above. The cerebral edema and tonsillar herniation of the patient was confirmed by cranial CT and MRI studies (Figures 1,2). The exact etiology of the edema that is related to imatinib has not yet been understood very well. Fluid retention and edema is an anticipated adverse effect of imatinib therapy especially when doses around 600$800 \mathrm{mg} /$ day are used. In clinical practice this is usually observed as periorbital and pretibial edema or as a gain in body weight. This side effect of the drug is sometimes not even taken notice of as it is usually mild or is treated by the administration of diuretics [5,6]. Nevertheless rarely encountered types of edema which may be peculiar to an organ or generalized may be life threatening.

The patient was on imatinib therapy due to CML in the chronic phase and as she was not receiving another drug therapy the brain edema was strongly thought to be due to imatinib. In literature there are two other reported cases that developed cerebral edema while on imatinib therapy. Both of the cases were taking imatinib at a dosage of $600 \mathrm{mg} /$ day at the time of initiation of symptoms unlike our patient

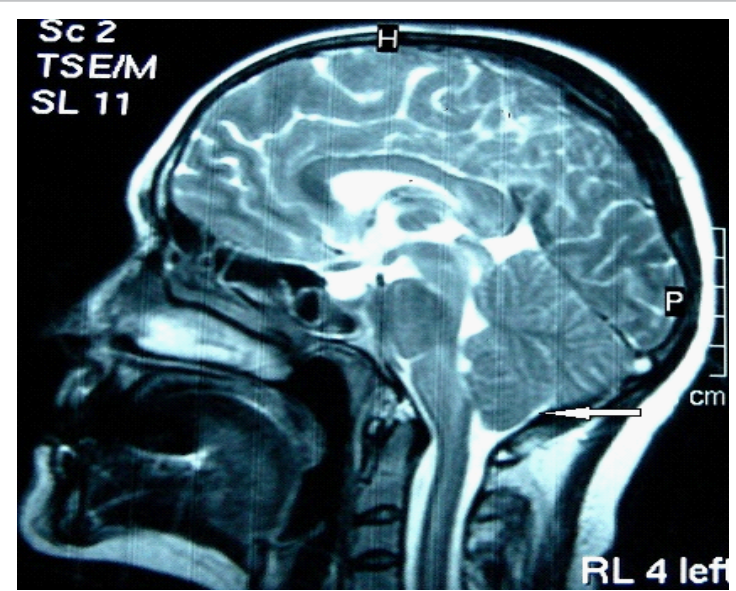

Figure 2: Cranial MRI with no contrast injection- diffusion MRI (03.12.2008): Volume increase and T2 signal augmentation in brain stem, mesencefalon, cerebellar hemispheres, corpus callosum and supratentorial subcortical white matter. Cerebellar tonsillar herniation is visible (white arrow). who was taking $400 \mathrm{mg} /$ day imatinib. As discussed earlier, edema is much frequently observed at higher doses of imatinib such as $600-800$ $\mathrm{mg} /$ day. Symptoms of cerebral edema developed 3 months and 4 weeks after the initiation of therapy in these two cases, respectively. Our patient had been taking imatinib for 15 days when she was diagnosed with cerebral edema. In one of the cases, imatinib was stopped after cerebral edema ensued and after recovery of symptoms imatinib was restarted at $400 \mathrm{mg} / \mathrm{day}$, but cerebral edema recurred and he died one month later like our patient. But in the other case, after disappearance of cerebral edema imatinib was restarted at $300 \mathrm{mg} /$ day without reappearance of cerebral edema and she even tolerated imatinib at a dosage of $800 \mathrm{mg} /$ day (17).

As other types of edemas associated with imatinib, the etiology of brain edema has not been ascertained yet. There are some studies purporting the reason for edema and fluid retention to be due to PDGFR inhibition by the use of imatinib. One of these studies puts forward the regulation of the interstitial fluid homeostasis by the PDGFR via P13K (phosphatidylinositol-3' kinase). Stimulation of the P13K activity lowers the intratumoral fluid pressure [18]. Many tumoral formations have interstitial hypertension that complicates the entrance of the antitumoral drugs into the tumoral tissue. It has been purported that interstitial fluid pressure is increased by the expression of the PDGFR- $\beta$ signal and as this expression is inhibited by imatinib the interstitial hypertension is lowered and the solutes' transport through the capillaries to the interstitium is increased [19]. This has been demonstrated by the increase of the passage of 51Cr-EDTA through the capillaries into the interstitium [19]. According to this it can be adduced that the decrease in the pressure of the interstitium may lead to fluid transfer to the interstitium and give rise to the edema formation. A recent study has demonstrated in humans with various solid tumors that the blockage of PDGFR- $\beta$ by CDP-860 (humanized, PEGylated di-Fab') have led to fluid retention and edema [20]. All these studies bring forward that the inhibition of PDGFR- $\beta$ plays a role in fluid retention and edema formation. The investigation of the signal transmission association between the PDGFR- $\beta$, P13K and $\mathrm{Na} / \mathrm{K}$ ATPase may prove to be quite interesting. We believe that there are some differences between fluid retention in cavities and edema formation. Fluid retention in cavities may be due to an alteration in the capillary permeability of an unknown reason.

The edema associated with imatinib is formed by the accumulation of fluid in the interstitial tissue however it is not very clear whether brain edema is due to an increase in the interstitial or intracellular fluid. This context has not been described in the previous brain edema cases either [17]. We were unable to clarify this controversy as no autopsy and histologic studies could have been performed on the patient, however the MRI study did not put forward any findings in favor of hemorrhage or leukemic infiltration. It is not clear and not well understood why fluid retention and edema formation is not encountered in all patients under imatinib therapy or why the localizations differ from person to person. This can be associated with a second triggering mechanism may be present. Polymorphisms of PDGFR genes do not appear to play a role in patient's susceptibility to clinically severe edema formation during treatment with imatinib [21].

\section{Conclusion}

The clarification of the mechanism inducing this problem will help to prevent the formation of such fatal side effects. Furthermore the possibilities for the use of other tyrosine kinase inhibitors in patients in whom edema is formed by the use of imatinib needs to be investigated. 
Citation: Mehtap O, Atesoglu EB, Tarkun P, Hacihanefioglu A, Keski H, et al. (2012) A Rare but Fatal Complication Probably due to Imatinib: Cerebral Edema. J Clin Case Rep 2:176. doi:10.4172/2165-7920.1000176

\section{References}

1. Buchdunger E, Cioffi CL, Law N, Stover D, Ohno-Jones S, et al. (2000) Ab protein-tyrosine kinase inhibitor STI571 inhibits in vitro signal transduction mediated by c-kit and platelet-derived growth factor receptors. J Pharmacol Exp Ther 295: 139-145.

2. Druker BJ, Tamura S, Buchdunger E, Ohno S, Segal GM, et al. (1996) Effects of a selective inhibitor of the Abl tyrosine kinase on the growth of Bcr-Abl positive cells. Nat Med 2: 561-566.

3. Druker BJ, Guilhot F, O'Brien SG, Gathmann I, Kantarjian H, et al. (2006) Fiveyear follow-up of patients receiving imatinib for chronic myeloid leukemia. $\mathrm{N}$ Engl J Med 355: 2408-2417.

4. O‘Brien SG, Guilhot F, Larson RA, Gathmann I, Baccarani M, et al. (2003) Imatinib compared with interferon and low-dose cytarabine for newly diagnosed chronic-phase chronic myeloid leukemia. N Engl J Med 348: 994-1004.

5. Druker BJ, Talpaz M, Resta DJ, Peng B, Buchdunger E, et al. (2001) Efficacy and safety of a specific inhibitor of the BCR-ABL tyrosine kinase in chronic myeloid leukemia. N Engl J Med 344: 1031-1037.

6. Druker BJ, Sawyers CL, Kantarjian H, Resta DJ, Reese SF, et al. (2001) Activity of a specific inhibitor of the BCR-ABL tyrosine kinase in the blast crisis of chronic myeloid leukemia and acute lymphoblastic leukemia with the Philadelphia chromosome. N Engl J Med 344: 1038-1042.

7. van Oosterom AT, Judson I, Verweij J, Stroobants S, Donato di Paola E, et al. (2001) Safety and efficacy of imatinib (STI571) in metastatic gastrointestinal stromal tumours: a phase I study. Lancet 358: 1421-1423.

8. Demetri GD, von Mehren M, Blanke CD, Van den Abbeele AD, Eisenberg B, et al. (2002) Efficacy and safety of imatinib mesylate in advanced gastrointestinal stromal tumors. N Engl J Med 347: 472-480.

9. Breccia M, Carmosino I, Russo E, Morano SG, Latagliata R, et al. (2005) Early and tardive skin adverse events in chronic myeloid leukaemia patients treated with imatinib. Eur J Haematol 74: 121-123.

10. Esmaeli B, Prieto VG, Butler CE, Kim SK, Ahmadi MA, et al. (2002) Severe periorbital edema secondary to STI571 (Gleevec). Cancer 95: 881-887.

11. Fraunfelder FW, Solomon J, Druker BJ, Esmaeli B, Kuyl J (2003) Ocular side- effects associated with imatinib mesylate (Gleevec). J Ocul Pharmacol Ther 19: 371-375.

12. Breccia M, Gentilini F, Cannella L, Latagliata R, Carmosino I, et al. (2008) Ocular side effects in chronic myeloid leukemia patients treated with imatinib. Leuk Res 32: 1022-1025.

13. Kusumi E, Arakawa A, Kami M, Kato D, Yuji K, et al. (2004) Visual disturbance due to retinal edema as a complication of imatinib. Leukemia 18: 1138-1139.

14. Shimazaki C, Ochiai N, Uchida R, Fuchida SI, Okano A, et al. (2003) Intramuscular edema as a complication of treatment with imatinib. Leukemia 17: 804-805.

15. Breccia M, D'Elia GM, D'Andrea M, Latagliata R, Alimena G (2005) Pleuralpericardic effusion as uncommon complication in $\mathrm{CML}$ patients treated with Imatinib. Eur J Haematol 74: 89-90.

16. Moore JC, Dennehey CF, Anavim A, Kong KM, Tiong Ong S (2006) Multiple joint effusions associated with high-dose imatinib therapy in a patient with chronic myelogenous leukaemia. Eur J Haematol 76: 444-446.

17. Ebnoether M, Stentoft J, Ford J, Buhl L, Gratwohl A (2002) Cerebral oedema as a possible complication of treatment with imatinib. Lancet 359: 1751-1752.

18. Heuchel R, Berg A, Tallquist M, Ahlen K, Reed RK, et al. (1999) Plateletderived growth factor beta receptor regulates interstitial fluid homeostasis through phosphatidylinositol-3' kinase signaling. Proc Natl Acad Sci U S A 96: 11410-11415.

19. Pietras K, Ostman A, Sjoquist M, Buchdunger E, Reed RK, et al. (2001) Inhibition of platelet-derived growth factor receptors reduces interstitial hypertension and increases transcapillary transport in tumors. Cancer Res 61: 2929-2934.

20. Jayson GC, Parker GJ, Mullamitha S, Valle JW, Saunders M, et al. (2005) Blockade of platelet-derived growth factor receptor-beta by CDP860, a humanized, PEGylated di-Fab', leads to fluid accumulation and is associated with increased tumor vascularized volume. J Clin Oncol 23: 973-981.

21. Bruck P, Wassmann B, Lopez ER, Hoelzer D, Ottmann OG (2004) Development of hygromas or severe edema during treatment with the tyrosine kinase inhibitor STI571 is not associated with platelet-derived growth factor receptor (PDGFR) gene polymorphisms. Leuk Res 28: 1153-1157. 